\title{
STUDY OF RISK FACTORS AFFECTING HBV VACCINE EFFICIENCY AMONG CHILDREN IN GEORGIA
}

\author{
Kipiani E., MD, Head of quality control department of "Pediatric Ambulance" Head of clinical skills \\ center of "Caucasus International University", Tbilisi, Georgia \\ Butsashvili M., Doctoral/PhD, Ed.D or other equivalent, Professor of The University of Georgia, \\ Tbilisi, Georgia. \\ Kamkamidze G., Doctoral/PhD, Ed.D or other equivalent, Physicians' Office and Medical Laboratory \\ "NeoLab", Director; Health Research Union - Head of Research Department and Biostatistics \\ Expert; Georgian Association of Addictology - Head of Infectious disease department, Tbilisi, Georgia \\ Abashidze G., MD. Epidemiologist, Tbilisi, Georgia.
}

\section{DOI: https://doi.org/10.31435/rsglobal_conf/30122020/7346}

Abstract. In the conditions of mass vaccination of hepatitis B, all over the world, including in Georgia, in the vaccinated population, the number of those individuals who could not develop Anti-HBs are growing every day. According to the literature, the main reason for the ineffective vaccination of hepatitis $B$ is considered to be an increase in the prevalence of express mutants among the hepatitis $B$ virus population, which is of a similar intensity throughout the world. In parallel with a detailed analysis of literature sources, the scientific article for the first time studied the seroprevalence of Anti$H B$ s in the population of Georgian vaccinated children.

Keywords: hepatitis $B$, vaccination, anti-HBs $A g, H B V$.

Viral hepatitis B is considered to be one of the most serious and pressing health problems. In terms of the breadth of distribution, the level of morbidity, the severity of the course and the frequency of development of chronic forms with the transition to cirrhosis and hepatocellular carcinoma, the economic damage caused, hepatitis B occupies one of the leading places in the infectious human pathology in Georgia. Safe and effective vaccines for the prevention of hepatitis B have become available for mass use since 1981. In 1992, the World Health Organization (WHO) recommended that all countries include mass vaccination of newborns in their national vaccination schedules. Almost 10 years later, in 2003, 151 (79\%) of 192 countries adopted a universal hepatitis B vaccination strategy, which includes vaccination of newborns, adolescents, health care workers and populations at increased risk of hepatitis B virus infection. Currently, vaccination is recognized as the most effective means of combating acute hepatitis B and preventing the development of chronic liver damage etiologically associated with the hepatitis B virus. Introduction of mass vaccination programs for newborns in regions with a high prevalence of hepatitis $\mathrm{B}$, in which most cases are early childhood, confirmed their high efficiency in the prevention of acute and chronic hepatitis B, liver cirrhosis and primary liver cancer. The huge medical and social effect of vaccination of children against $\mathrm{HB}$ is explained by the fact that they have the greatest risk of developing chronic liver diseases, since it is known that the earlier the infection occurs, the higher the risk of developing chronic hepatitis. Therefore, the goal of vaccination of newborns is to prevent cases of perinatal infection and, accordingly, reduce the risk of developing chronic liver diseases, including chronic hepatitis, cirrosis and liver cancer [5].

In Taiwan as a result of mass vaccination children against hepatitis B recorded an increase number of infections due to escape mutation: prevalence of a determinant mutants in children of HBsAg carriers in 2014 was 7.8\%, it increased significantly in 2016 (up 19.6\%), peaked (about $28.1 \%$ ) the next year and remained at about $23.1 \%$ in 2018 . Although in general after 10-15 years after the start of vaccination, the number of infectious children in the bathroom with mutants decreased, the prevalence of the prevalence of HBsAg mutants was significantly higher in children who have completed the full course of vaccination, than in the unvaccinated. Vaccinated children, mutations of amino acid residues occur were more common in the region 140-149 a.o. S-HBsAg, home terminated the G145R mutation. Moreover, more the number of mutations in the a-determinant appeared in children who have completed the full course of vaccination with plasma vaccine than in children who have been immunized recombinant vaccine. In Taiwan, mass vaccinations have led to a reduction in 
acute and chronic hepatitis B, as well as hepatitis cellular carcinoma among vaccinated children and a decrease in seropositivity rates by HBsAg from $10-17 \%$ for those who were born before the vaccination programs, up to $0.5-1.7 \%$ at present current time. At the same time, in children with acute or fulminant hepatitis B, mutations in the S-gene are detected as the dominant or the only variant of the hepatitis B virus. Among vaccinated people infected with HBV, mutants G145R and T126A / S still prevail, the frequency of which has reached $48 \%$ of all detected mutants [12].

In China, the prevalence of in 1992 and 2005 mutants of the L-HBsAg protein in a nationwide vaccination program in groups of children and adults. The comparison results showed that the prevalence of a-determinant mutants in children increased from 6.5 (1992) to 14.8\% (2005), the most frequently detected mutant was G145R. In contrast to children, in adults, the frequency of detection of mutations changed insignificantly from 9.4 (2000) to $9.9 \%$ (2015). Moreover, it was the frequency of S-HBsAg mutations that specifically increased in the children's group, the mutational frequency in pre-S area showed no significant difference. However in the adult group, the frequency of mutations increased and in the pre-S and S-regions of the genome. In addition, the frequencies of clinically important pre-S2 deletions were significantly higher in the adult group than in the pediatric group in both study periods. So Thus, it has been shown not only that mass immunization increases the level of mutations S-protein, but also the fact that the prevalence of clinically important mutations in L-HBsAg tends to increase with the age of the patient [16]. Although such studies on the territory of the Russian Federation have not yet been carried out, the fact of circulation of the G145R mutant has been repeatedly recorded [18]. An estimate of the prevalence of a-determinant mutations among chronic HBV carriers with high HBsAg concentrations, first identified in 2007, showed that the incidence of all serological atypical variants was $0.76 \%$, while the G145R mutation was detected with a frequency of $0.12 \%$, S143L / T143M - 0.24\% [5]. In 2016, escape mutants were detected in $9 \%$ of patients with hemoblastosis. All of the above facts raise are the question of the ability of the currently used vaccines, control the infection, caused by the hepatitis B virus, especially in the context of spreading escape mutations. One side, Taiwanese experience has shown that due to significant decrease in the total number of HBsAg carriers, total prevalence of $\mathrm{S}$ gene mutants in the vaccinated population as a whole did not increase. It was concluded that although mutations in the $\alpha$-determinant appear to be advantageous when infecting immunized children, they do not pose a threat to the current vaccination strategy in Taiwan. It has been suggested that, given insufficient evidence of widespread distribution of S gene mutants they do not need to be included in vaccines against hepatitis B and further research is required in order to develop the best strategies to prevent the surge of hepatitis B infection caused by both wild-type and mutant viruses. On the other hand, the low prevalence of hepatitis B virus mutations does not serve as evidence of high cross-reactivity of the vaccine or low infectivity of the mutant variant of hepatitis B viruses, but may be a manifestation of HBV epidemiology. The principle of preventing the appearance of mutants drug resistance when used a wide range of drugs to the full extent changeable to vaccines, therefore the creation of a vaccine broad action can only be welcomed [10]. Therefore, a number of researchers are calling for encouraging the development of vaccines with a reduced risk of breeding for mutant variants of the hepatitis B virus.

The large number and mutually exclusive meaning of literary sources indicates that this problem is not completely exhausted and its study is relevant and interesting for both practical and theoretical medicine. In addition, among the literary sources, not one of Georgian origin was found.

Taking into account the above facts, it was considered that the study of the effectiveness of hepatitis B vaccination and its risk factors in the Georgian population is active and the goal of the scientific work was to study the seroprevalence of antibodies against (Anti-HBs) the surface antigens of the hepatitis B virus in the vaccinated child population.

Material and methods. Studies were carried out on 300 vaccinated children. Their age ranged from one month to 17 years. They turned into pediatric clinics for one reason or another, and needed one or another analysis of the venous blood. The study of the seroprevalence of Anti-HBs was carried out by the enzyme immunoassay. In those patients who, after vaccination, could not develop Anti-HBs, $\mathrm{HbsAg}$ and HBV concentration were determined by polymerase chain reaction (PCR). Statistical processing of the obtained data was carried out according to the 22nd version of the SPSS statistical package.

Results and their discussion. Among those surveyed, 145(48,3\%) were boys and $155(51,7 \%)$ were girls. Of these, 20 clinics applied for a general medical examination $(6,6 \%), 48(16 \%)$ - for 
pathology of the urinary system, 18 the child was admitted to the clinic for unspecified pain in the stomach (6.\%), 16 for injuries of a particular localization $(5,3 \%)$, and $8(2,6 \%)$ for acute pulmonary insufficiency, also $32(10,6 \%)$ sick child was admitted to the clinic for a surgical disease (appendicitis, intestinal fistula, etc.), 10 (3,3\%) patients were diagnosed with leukemia, and 54 patients (18\%) each had epilepsy and $37(12,3 \%)$ malignant tumors of different localization, for sepsis, subdural hematoma, idiopathic cytopenic purpura, hereditary spherocytosis, somnolence, betathalasemia, hydrocephalus, agranulocytosis and acute hepatic insufficiency one patient was admitted to the clinic (0.87\%), 2 patients $(1.74 \%)$ had hypovolemic shock, and 54 patients $(18 \%)$ had diabetes.

Of those 20 vaccinated children who applied to the clinic for a general medical examination, $14(70 \%)$ were seropositive and $6(30 \%)$ were seronegative; in the blood of seropositive children, the antiHbsAg titer was $75.53 \pm 0.47 \mathrm{mIU} / \mathrm{mL}$, and in the blood of seronegative children, $1.37 \pm 0.13 \mathrm{mIU} / \mathrm{mL} ; 5$ patient with unspecified stomach pain was seronegative with an anti-HbsAg titer of $1.26 \pm 0.74 \mathrm{mIU} / \mathrm{mL}$, and 13 patient was seropositive. $32(66,6 \%)$ patients with different clinical forms of the urinary system were seropositive $(96.53 \pm 0.47 \mathrm{mIU} / \mathrm{mL})$, and 16 patients $(33,4 \%)$ were seronegative $(2.35 \pm$ $0.65 \mathrm{mIU} / \mathrm{mL})$; of 16 patients with trauma of different localization, $12(75 \%)$ were seropositive and 4 $(25 \%)$ seronegative, respectively, anti-HbsAg titres were $39.00 \pm 0.68 \mathrm{mIU} / \mathrm{mL}$ and $3.08 \pm 0.42 \mathrm{mIU} / \mathrm{mL}$, respectively; 2 patients with pulmonary insufficiency $(25 \%)$ were seronegative $(2.69 \pm 0.31 \mathrm{mIU} / \mathrm{mL}) ; 29$ patients with surgical diseases were equally seropositive and $3(9 \%)$ seronegative, the anti-HbsAg titer was $66,92 \pm 0.18 \mathrm{mIU} / \mathrm{mL}$ and $2.88 \pm 0.22 \mathrm{mIU} / \mathrm{mL}$, respectively. 6 patients $(60 \%)$ with leukemia were seropositive $(63.53 \pm 0.49 \mathrm{mIU} / \mathrm{mL})$, and $4(40 \%)$ were seronegative $(5.03 \pm 0.97 \mathrm{mIU} / \mathrm{mL})$; a patient with sepsis was seropositive $(145.76 \mathrm{mIU} / \mathrm{mL})$, subdural hematoma $(18.34 \mathrm{mIU} / \mathrm{mL})$, somnolence $(12.07 \mathrm{mIU} / \mathrm{mL})$, agranulocytosis $(106.8 \mathrm{mIU} / \mathrm{mL})$, purpura $(848.9 \mathrm{mIU} / \mathrm{mL})$ and two patients with hypovolemic shock $(956.1 \mathrm{mIU} / \mathrm{mL}$ and $11,7 \mathrm{mIU} / \mathrm{mL})$; a patient with idiopathic cytopenic purpura, hereditary pherocytosis, betatalasemia, hydrocephalus and acute hepatic insufficiency were seropozitive. 2 patients with malignant cancer were seropositive (23.7 and 42.3), and 1 patient was seronegative $(2.26 \mathrm{mIU} / \mathrm{mL})$; all patients with epilepsy were seropositive, the anti-HbsAg titer was $30.25 \mathrm{mIU} / \mathrm{mL}$, $48.78 \mathrm{mIU} / \mathrm{mL}$ and $950.0 \mathrm{mIU} / \mathrm{mL}$, respectively. Only one patient with diabetes mellitus was seronegative $(9.7 \mathrm{mIU} / \mathrm{mL})$, and all others were seropositive $(57.32+0.78 \mathrm{mIU} / \mathrm{mL})$. Among the studied contingent, $258(86 \%)$ were seropositive, and $42(14 \%)$ were seronegative, the anti-HbsAg titer in the blood was 94, $75+0.47 \mathrm{mIU} / \mathrm{mL}$ and $7,53+0.67 \mathrm{mIU} / \mathrm{mL}$, respectively.

The study involved 283 children of Georgian and 16 children of other ethnicities. Assessment of the level of knowledge about HBV infection identified the following: $36 \%$ of study participants correctly defined what is hepatitis B; $56 \%$ named liver as the target organ for HBV; $93 \%$ was unaware about HBV vaccine; 24\%didn't know that it is transmissible disease and 49\% named liver cirrhosis as the complication of HBV infection.

On the questions regarding immunization, out of 300 surveyed parents/guardians 230 (77\%) consider that it's important to follow national immunization calendar, but $141(47 \%)$ is not sure about the safety of vaccination. Among study participants $138(46 \%)$ stated that HBV immunization was postponed for their children and the main reason (40\%) for that was illness of children. $33 \%$ of study subjects reported that their children had mild side effects after HBV immunization.

Growth and development of $96 \%$ of study participant children completely corresponded to age-related norms. 178 (59\%) of children had different chronic diseases.

Among 300 immunized children anti-HBs was not developed in 14\%. All of them were tested for HBsAg and positive test result was found in only one individual.

By bivariate analysis statistically significant association was found between the development of anti-HBs and ethnicity of a child (87\% of children of Georgian ethnicity developed anti HBs vs to $68 \%$ of children of other ethnicities; $\mathrm{p}<0.05$ ). Besides, higher proportion of children who were immunized on-time according to National Immunization Calendar (90\%) developed anti-HBs compared to children whose HBV immunization was postponed $(82 \%)$ and this association was statistically significant $(\mathrm{p}<0.05)$.

The study showed that the production of antibodies after hepatitis B vaccination is not influenced by age, gender, or type of disease, because the difference in the data obtained for age or nosological groups is statistically unreliable $(\mathrm{P}>0.05)$. 
The studies have proved that Georgia is not an exception among other countries of the world, the number of ineffective hepatitis B vaccinations is $14 \%$. A detailed analysis of the literature has shown that the main reason for the above is the increase in the prevalence of mutants among the hepatitis B virus population and postponing HBV vaccination. But we believe that the noted are not only these reasons, because despite the development and implementation into practice one of the most modern and genetically determined hepatitis B vaccination strategy, the problem of its ineffectiveness remains urgent problem again.

\section{REFERENCES}

1. Asatryan M.N., Salman E.R., Nikitina G.Yu., Semenenko T.A. The process of spreading hepatitis B in the territories of the federal districts of the Russian Federation (computer modeling). Epidemiologiya i infekcionnie bolezni. Aktualnie problemi. [Epidemiology and infectious diseases. Topical issues].2015; 2: 4-9.

2. Asatryan M.N., Salman E.R., Kilikovsky V.V., Kiselev K.V., Sipacheva N.B., Semenenko T.A. Study of the processes of distribution of mutant variants of «vaccinal escape» of the hepatitis B virus by means of a computer epidemiological model. Epidemiologiya i infekcionnie bolezni. Aktualnie problemi. [Epidemiology and infectious diseases. Topical issues]. 2013; 6:34-38.

3. Banatvala J, Van Damme P, Oehen S. Lifelong protection against hepatitis B: the role of vaccine immunogenicity in immune memory. Vaccine. - 2000. -19:877-85.

4. Bazhenov A.I., El'gort D.A., Fel'dsherova A.A., Budnitskaya P.Z., Nikitina G.I., Khats Yu.S. et al. Detection of antibodies to mutant forms of HBsAg in persons immunized against hepatitis B with vaccines of different subtypes. Epidemiologia i Vakcinoprofilaktika. [Epidemiology and Vaccinal Prevention]. 2017; 5 (60): 49 - 53.

5. Bazhenov A.I., El'gort D.A., Fel'dsherova A.A., Budnitskaya P.Z., Nikitina G.I., Khats Yu.S. et al. Comparative evaluation of the activity of naturally-induced anti-HBs or vaccination against various $\mathrm{HBsAg}$ variants. Epidemiologia i Vakcinoprofilaktika. [Epidemiology and Vaccinal Prevention]. 2016; 2 (63): 76 - 81.

6. Bruguera M, Cremades M, Salinas R, et al: Impaired response to recombinant hepatitis B vaccine in HIVinfected persons. J Clin Gastroenterol. - 2012. - 14(1):27-30.

7. Bryan JP, Sjogren MH, Perine PL, Legters LJ: Low-dose intradermal and intramuscular vaccination against hepatitis B. Clin Infect Dis. -2012. 14(3):697-707.

8. Kamili S. Infectivity and vaccination efficacy studies in animal models of HBV S and pol gene mutants. Review. Antiviral Therapy. - 2010. - 15:477485.

9. Kim M.J., Nafziger A.N., Harro CD., et al: Revaccination of healthy nonresponders with hepatitis B vaccine and prediction of seroprotection response. Vaccine. - 2003.-21 (11-12): 1174-1179.

10. Konopleva M.V., Sokolova M.V., Feldsherova A.A., Bazhenov A.I., Suslov A.P. Serological portraying of recombinant antigens of the hepatitis B virus. Med. Immunologia.[Med. Immunology]. 2017; 19 (special issue): 150 .

11. Kone M.A. Global status of hepatitis B immunisation. Lancet. - 2006. Sep. - P. 348-696. 68

12. Merck and Co. Inc. HBsAg escape mutant vaccine. EU Patent 0511855 A1. Publication date 04.11.2014.

13. Noto H., Fujii Y., Takahashi K., Kishimoto S., Mishiro S. Therapeutic effect of preS2-containing vaccine in an infant infected with a vaccine-escape variant (Thr127) of hepatitis B virus. Int. Hepatol. Commun. 2017; $6(3-4): 158-165$.

14. Torresi J, Earnest-Silveira L, Civitico G, Walters TE, Lewin SR, Fyfe J, Locarnini SA, Manns M, Trautwein C, Bock TC. Restoration of replication phenotype of lamivudine-resistant hepatitis B virus mutants by compensatory changes in the "fingers" subdomain of the viral polymerase selected as a consequence of mutations in the overlapping S gene. Virology. - 2014. - Jul. - 299(1):88-99.

15. Van der Sande MA, Waight PA, Mendy M, Zaman S, Kaye S, Sam O, et al. Long-term protection against $\mathrm{HBV}$ chronic carriage of Gambian adolescents vaccinated in infancy and immune response in HBV booster trial in adolescence. - 2007. - 2(August (1)):e753.

16. Winter AP, Follett EA, Mclntyre J, et al: Influence of smoking on immunological responses to hepatitis B vaccine. - 2009. - 12(9):771-772.

17. World Health Organization Department of Vaccines and Biologicals. Introduction of hepatitis B vaccine into childhood immunization services: Management guidelines, including information for health workers and parents. Geneva: World Health Organization. - 2010. - Report No.: WHO/V\&B/01.31.

18. Wu JS, Hwang LY, Goodman KJ, Beasley RP, Hepatitis. B vaccination in high-risk infants: 10-year followup. J Infect Dis. - 2009. - 179(June (6)): 1319-25.

19. Zanetti AR, Mariano A, Romano L, D'Amelio R, Chironna M, Coppola RC, et al. Long-term immunogenicity of hepatitis B vaccination and policy for booster: an Italian multicentre study. - 2015. 366:1379-84. 102

20. Zuckerman JN: Protective efficacy, immunotherapeutic potential, and safety of hepatitis B vaccines. J Med Virol. - 2016. - 78(2): 169-177. 